\title{
La detecció de necessitats de formació com a punt de partida per a la seva transferència a la pràctica educativa
}

\author{
Joan Fuguet Busquets \\ Universitat Rovira i Virgili \\ juan.fuguet@urv.cat
}

Resum: En aquest treball s'hi reflexiona sobre la importància del procés de detecció de les necessitats de formació permanent del professorat que es realitza en els centres educatius d'infantil i primària i la influència que té en la posterior transferència de les habilitats $i$ els coneixements adquirits a la pràctica educativa a l'aula.

S'hi analitzen els models de formació que planteja l'administració educativa i els processos d'avaluació que han de verificar l'eficàcia de les accions formatives i la seva incidència en la millora de la qualitat del centre.

Les dades recollides durant la investigació han permès copsar la percepció que el professorat té de com es realitzen els processos per desenvolupar les accions formatives als centres i les seves expectatives sobre la millora de la seva pràctica educativa $i$ la influència en la millora dels aprenentatges dels seus alumnes.

Paraules clau: formació, transferència, avaluació, necessitats, professorat.

Abstract: This study reflects on the importance of detecting the lifelong training needs of infant and primary school teachers and the influence this has on the subsequent transfer of new skills and knowledge to teaching practice in the classroom.

It analyzes the training models used by the educational administration and the evaluation processes that are designed to verify the efficacy of training activities and their ability to improve the quality of an educational centre.
The data collected during the research highlight the perception of the teaching staff regarding the processes for carrying out training activities in educational centres and their expectations regarding how their own teaching practice and the learning of the students will be improved.

Key words: training, transfer, evaluation, needs, teachers.

\section{Introducció}

En el marc d'una investigació realitzada a l'escola de Bonavista i a l'escola de Pràctiques de la demarcació de Tarragona, a fi d'indagar quina era la percepció dels docents sobre la transferència de la formació permanent a la seva pràctica educativa a l'aula, s'hi va palesar la importància del procés de detectar les necessitats de formació del centre, com a punt de partida d'un llarg camí que ha de fer que el docent canviï de conducta en la seva tasca a l'aula, i hi apliqui els coneixements i les habilitats apreses.

Em situo en el context de les instruccions del Pla de formació 2009-10 (Generalitat de Catalunya 2009) dictades pel Departament d'Educació. Aquestes instruccions proposen que, en tots els serveis educatius de Catalunya, s'hi iniciïn processos que avaluïn l'efectivitat de la formació en relació amb els objectius de cada institució, i que també avaluïn la transferència dels continguts assolits a la pràctica docent, per tal de mesurar-ne la incidència com a mecanisme perquè els centres millorin i canviïn, més enllà d’avaluar el 
grau de satisfacció del professorat assistent, que és el que fins ara s'avaluava.

\section{Formació permanent del professorat}

Fins fa ben poc el model de formació predominant es caracteritzava per transmetre una teoria descontextualitzada i uniforme, allunyada dels problemes reals i basada en un docent estàndard que no existeix en la realitat i sense fer cas del discurs que la formació ha d'acostar-se a l'escola i que ha de donar resposta a la problemàtica que s'hi genera.

El principal problema d'aquest model és que no es produeix una contextualització ni al centre ni a l'aula i les dificultats per aplicar les habilitats i competències adquirides pel docent són, moltes vegades, insalvables (fomentar l'ús dels ordinadors, quan el centre no en té prou per a tots els alumnes; fomentar agrupacions d'alumnes, quan les plantilles de professors són escasses; etc.).

Posant la mirada en una nova perspectiva, el professorat ha de participar en tots els processos de planificació i execució de la formació, partint de les necessitats i els problemes que es generin a la seva aula, com a context educatiu més proper. El professor ha de creure que aquesta formació repercutirà en l'aprenentatge dels seus estudiants, perquè canviï les seves creences; per això, cal construir un nou concepte de formació que inclogui les emocions, la complexitat, l'autoformació, la comunicació, i deixi de banda la formació disciplinar d’altres èpoques.

Per tal que el professor doni suport a la nova reforma (LOE) que s'ha iniciat i als nous currículums, s'ha de comptar amb ell i amb el seu desenvolupament professional. Molts docents rebutgen les reformes i la formació, perquè no se'ls té en compte.

Cal rearmar moralment i intel-lectualment el professorat; per aconseguir-ho, cal que recuperi el control i sigui el protagonista de la seva formació en el seu context laboral (Imbernón 2007). I ens hem doposar a qualsevol manifestació explícita o oculta de racionalitat tècnica que ens torni al passat.

Cal generar un debat de l'actual situació i cal influir en noves propostes de formació perma- nent del professorat, en un marc d'una educació que estigui més polititzada i allunyada de la fal.làcia de la neutralitat (Freire 2004, citat per Imbernón 2007), que es basi en la llibertat de les persones i que parli d'una formació collaborativa i dialògica.

Davant d'aquest repte, quan parlem de models de formació que sadeqüin a la concepció actual de la formació permanent, hem de considerar que l'aprenentatge individual i l'organitzacional, han de ser un "contínuum" (Iranzo 2009). Per tant, les accions de formació han de donar resposta, d'una banda, a les necessitats professionals i, de l'altra, als requeriments socials de la professió.

Quan parlem del disseny dels programes de formació, s'hi ha d'incloure un aparat que s'hauria d'anomenar "l'impacte del programa", que inclouria l'aprenentatge dels participants (competències, sentiments, avaluacions de les seves experiències...), l'avaluació dels responsables sobre la seva efectivitat en els resultats de l'ensenyança i en els resultats dels alumnes (Fernández Cruz 1999:329 i seg., citat per Iranzo 2009). La mateixa autora es pregunta si caldria també, a l'hora de parlar de l'avaluació de l'impacte, l'aprenentatge que han realitzat els formadors.

Vull destacar, encara, que, quan parlem de desenvolupar un programa formatiu, s'hi han de tenir en compte les necessitats formatives que norienten el disseny i que fan referència a la competència docent, les informacions prèvies, els errors conceptuals i els altres obstacles per a l'aprenentatge professional.

Analitzar les diverses modalitats de formació ens pot fer pensar que s'han destinat molts recursos a dissenyar cursos de capacitació poc relacionats amb els contextos reals que hi ha a les escoles, i això, a més d'una veritable pèrdua econòmica, ha comportat una pèrdua de confiança del docent, cosa que ha passat molt en la modalitat que anomenem "curs de formació" i que quedava explicitada en les desercions que hi havia al llarg del curs.

Ara, en l'actualitat, els nous plans de formació plantegen uns models que anomenem "formació al centre". Aquests plans pretenen fer reflexionar sobre la pràctica, a partir d'un coneixement 
que se situa en el context de treball mateix, i que "l'aprendre a aprendre" doni resposta a la necessitat de ser actius en la construcció conjunta de significats (Iranzo 2009).

La formació ha de donar resposta a les situacions problemàtiques dels centres; per tant, s'han de crear espais de reflexió i participació perquè el professorat aprengui a través de l'estudi de la vida a l'aula i el centre. "No es poden formar els docents passivament, ja que ells es desenvolupen activament" (Day 2005, a Imbernón 2007:159); per això, es facilita més la innovació educativa si s'uneix la formació a un projecte de treball que no pas si es rep la formació i després se'n desenvolupa el projecte.

En el model de formació al centre, allò que es busca és, a partir d'analitzar acuradament les necessitats de canvi i millora del centre, desenvolupar projectes d'innovació, amb l'assessorament d'un expert extern que faciliti estratègies que afavoreixin la millora metodològica i organitzacional del centre.

\section{Transferència de la formació}

Quan utilitzo el concepte transferència, em situo dins dels processos d'avaluació de les accions formatives, i, per definir aquest concepte, ho faig d'acord amb el model dels quatre nivells de valoració (D. Kirkpatrick i J. Kirkpatrick 2006).

En el primer nivell s'hi analitza com reaccionen els participants en una acció formativa (reacció). Els autors remarquen la importància d'avaluar la reacció dels participants, ja que, d'aquesta manera, s'obté informació que permet millorar accions futures. També, en aquesta avaluació, s'hi dóna una retroalimentació en els formadors que n'afavoreix l'eficàcia, i això va lligat a poder saber què necessiten els potencials "clients de l'acció formativa".

He comprovat, amb la meva experiència com a formador, que es dóna, amb massa freqüència, la situació d'iniciar una acció formativa i detectar, molt aviat, una certa insatisfacció pel fet que els continguts o el format que es proposa no responen a les expectatives que s'havien format els assistents; per això, no s'han de rebutjar els qüestionaris de satisfacció que s'acostumen a passar en les accions formatives; però cal pensar que, segons els autors citats, només ens aporten informació d'un primer nivell d'avaluació.

En el segon nivell, hi hem d'avaluar si s'han complert els objectius d'aprenentatge, analitzant quins són els canvis en les capacitats, en els coneixements i en les actituds d'aquests participants (aprenentatge). Això implica recollir evidències de les activitats realitzades a l'aula i, a més, fer una comparativa amb els coneixements, les destreses i les actituds anteriors a l'acció formativa.

En el tercer nivell d'avaluació, s'hi ha de comprovar si s'han produït canvis en la conducta dels participants, com a conseqüència d'haver assistit a l'acció formativa (transferència dels coneixements, habilitats i actituds).

Aquí la resposta, segons els dos autors citats, és molt més complicada, ja que sí que podem afirmar que, sense aprenentatge, no hi ha possibilitats que el participant canviï la conducta en l'acció formativa; però el fet d'haver assolit l'aprenentatge tampoc no garanteix que hi hagi d'haver un canvi de conducta, ja que hi intervenen molts altres factors. El sistema organitzacional del centre on es desenvolupa la tasca educativa ha de permetre el canvi de conducta; els recursos i materials han de ser els adequats, i les "recompenses" han d'estimular la primera intenció del participant.

Quan parlem de recompenses, els mateixos autors parlen de les intrínseques - que són sentiments interns de satisfacció que es donen quan es canvia de cultura-i de les extrínseques - que inclouen diverses formes de suport i reconeixement, i també el fet que el centre prengui una sèrie de decisions, relacionades amb l'organització, que avalin la importància del canvi fet.

Lavaluació d’aquest tercer nivell (transferència dels aprenentatges a la pràctica a l'aula) és el pal de paller que avui han d'afrontar tots els agents implicats en la formació permanent del professorat, i el seu desenvolupament s'ha d'incloure en els futurs plans de formació del Departament d'Educació.

El quart nivell d'avaluació de les accions formatives, inclou saber els "beneficis", que, en el cas de la docència, són la millora en els resultats de l'aprenentatge dels alumnes i que els autors també anomenen l'impacte que ha tingut la formació en aquest aprenentatge. 
Seguint els mateixos autors, i en un intent de diferenciar els conceptes de transferència $i$ impacte, podríem parlar del primer com d'una influència immediata que fa referència a les evidències d'implementar les propostes de canvi metodològic en l'acció educativa a les aules, i del segon com el grau d'incidència de la formació més a llarg termini i que es basa en la consolidació de la millora i el canvi en el centre (resultats).

Per això, és important que, en els processos de formació, s'hi recullin evidències que les experiències dels professors a les aules, promogudes des de les tasques de formació, fomentin nous comportaments entre els seus alumnes i així s'activin les expectatives cap a la innovació (Iranzo 2009).

Un dels sentiments predominants en el professorat és la incertesa sobre l'impacte que la formació permanent exerceix en el seu alumnat. La complexitat de mesurar els resultats de l'aprenentatge, juntament amb altres influències que rep l'alumne (família, amics i societat), fa que l'avaluació que fa el professorat del seu impacte sobre l'alumnat sigui incerta (Lortie 1975, a Fullan 2002).

Lanàlisi de la incidència de la formació que es realitza als centres educatius és un tema poc explorat, malgrat les expectatives de canvi que generen els plans de formació. Sembla evident que la transferència de la formació a la pràctica educativa continua sent escassa, malgrat els programes i els esforços destinats a impulsar-la. També és evident el desconeixement sobre aquesta transferència i sobre la qualitat de la docència $i$ de l'educació en general.

El Pla marc de formació permanent 20052010, del Departament d'Educació, especifica que l'avaluació de la transferència de la formació "tracta de comprovar el grau en què els coneixements, les habilitats i les actituds apresos durant la formació es reflecteixen en la pràctica docent". (Generalitat de Catalunya 2005: 63).

Com hem dit, quan parlem de transferència i impacte de la formació permanent, ho podem fer des de diferents perspectives: des de l'efecte que té en l'àmbit dels coneixements, actituds i valors de l'alumnat; des de l'efecte que té en la metodologia que aplica el professorat a l'aula; des de l’efecte que té en la formació de manera que aquesta s'integri en el currículum i l'organització del centre, i des de l'efecte que té en la satisfacció del professorat (D. Kirkpatrick i J. Kirkpatrick 2006).

Per tant, l'avaluació de la transferència de la formació ha de posar en relleu la incidència que té en els centres, cercant indicadors que posin de manifest fins a quin punt hi influeix, tant en els aspectes organitzatius com en els processos d'ensenyament i d'aprenentatge de l'alumnat i en la millora professional del professorat.

També s'ha de tenir en compte que els mestres són persones en les quals conflueixen tres grans eixos: el docent (producte d'una determinada formació), la persona individual (amb la seva idiosincràsia, ideologia...) i l'integrant d'una comunitat docent determinada.

Segons Imbernón (2007), la falta de coordinació, de seguiment i d'avaluació per part de les institucions i serveis implicats en els plans de formació, l'ambigua orientació dels objectius, la manca de pressupost per a la formació autònoma dels centres educatius, la inadequació dels horaris (que sobrecarreguen i intensifiquen la tasca docent), la transformació del rol del formador expert en el de formador acompanyant, la manca de contextualització i la manca d'incentiu de millora professional, tot són obstacles que dificulten aquesta transferència.

\section{Lanàlisi de les necessitats de formació del centre}

Si parteixo de la idea d'Imbernón (2007): el professorat ha de participar en tots els processos de planificació i execució de la formació, partint de les necessitats i els problemes que es generin en la seva aula, l'estudi que hem realitzat demostra que aquesta participació es limita a discutir i després a aprovar, en l'àmbit dels equips de cicle i de Claustre, les propostes formatives que l'equip directiu hagi elaborat i presentat als equips de mestres del seu centre.

En alguns casos, sobté la informació a través d'enquestes o qüestionaris; però no hem trobat que existeixi un protocol de detecció de necessitats que orienti sobre les propostes de formació que els centres han d'incloure en els seus plans de formació, i tampoc no hem detectat que els 
màxims responsables (directora i director) ho tinguin com una prioritat en el seu projecte de centre.

Un 50\% dels docents manifesten que han participat en el procés de detecció de necessitats de formació; però, en les entrevistes, manifesten que les propostes responen a modes o bé a canvis normatius que estableix el mateix Departament d'Ensenyament, i així observem que la implantació del currículum LOE o bé la instal-lació de pissarres digitals tenen un pes remarcable dins dels plans de formació dels centres per als propers tres cursos i que es torna a caure en propostes de formació que, segons el mateix autor, són de caire disciplinari o tècnic.

Això fa que les expectatives que tenen la majoria de mestres de la mostra sobre la seva participació en activitats de formació permanent que pretenen millorar la seva pràctica educativa, per tal d'influir més eficaçment en el treball amb els seus alumnes, no es vegin complides en molts casos, perquè no hi ha una veritable correspondència entre les necessitats formatives pròpies $i$ compartides i la formació rebuda.

D'altra banda, hem constatat, en la discussió del grup d'experts, que l'Administració, a través dels plans de formació dels centres, presenta eines que han d'afavorir aplicar processos que detectin les necessitats que els docents vinculin a la presa de decisions davant d'un compromís comú i, a més, facilita que es formin els responsables dels centres que han d'impulsar aquests plans (directors i caps d'estudis).

\section{Conclusions}

És imprescindible que es prengui consciència, des dels centres, de la importància d'implicar el professorat en la confecció del Pla de formació de centre, sota el lideratge de l'equip directiu. La complicitat individual o col-lectiva dels equips de mestres a l'hora d'assolir els objectius estratègics de formació de cada centre és una peça clau a l'hora de cobrir les necessitats en clau educativa.

Un d'aquests objectius ha de ser garantir que la formació rebuda tingui incidència a l'aula i en l'organització i gestió del centre, a partir d'un bon procés d'avaluació de la transferència, i, per tant, s'ha de garantir una bona planificació de totes les actuacions a l'hora d'executar el Pla.

Un dels punts claus en aquesta planificació és realitzar un bon procés de detecció de necessitats de formació, partint d'una exhaustiva anàlisi del context, i determinar l'estat de la qüestió, recollint les inquietuds personals i col-lectives dels equips docents i de la comunitat educativa en general. Aquí és quan cal buscar el màxim consens entre els professors, però tenint en compte sempre els objectius estratègics del centre explicitats en el seu PEC.

A través de diferents tècniques que promoguin la col-laboració o utilitzant diferents instruments de recollida de dades, els equips directius han de detectar les necessitats, prioritzar-les i categoritzar-les, a fi que les pugui exposar al Claustre i aquest pugui decidir quins àmbits de formació desenvoluparà el Pla.

Els centres escolars han de tenir molt clares quines són les seves prioritats específiques i quins han de ser els processos, dins de la seva autonomia de gestió, per generar propostes de formació que realment responguin a una necessitat compartida pel seu collectiu de docents. Això garantirà la seva transferència a les aules. Cal també que els equips directius aconsegueixin compromisos col-lectius per millorar la qualitat del centre i redueixin la distància entre els objectius generals especificats al PEC i les tasques individuals que els mestres realitzen a les aules.

\section{Bibliografia}

Fullan, M. (2002). Los nuevos significados del cambio en la educación. Barcelona: Octaedro.

Generalitat de Catalunya (2005). Pla marc de formació permanent del professorat 20052010. Barcelona: Departament d'Educació. Consulta en línia: <htpp://www.xtec.cat/formació $>$.

- (2009). Pla de formació de zona. Criteris i instruccions 2009-2010. Barcelona: Departament d'Educació. Consulta en línia: <htpp://www. xtec.cat/formació>.

- (2009). Transferència de la formació en centre ICE (UAB, UB, UdL, UdG i URV). Barcelona: Departament d'Educació. 
- (2009). Programa de formació del personal docent. Barcelona: Departament d'Educació. Consulta en línia: <htpp://www.xtec.cat/formació> $>$.

IMBERNón, F. (2007). La formación permanente del profesorado. 10 ideas clave. Barcelona: Graó.

Iranzo, P. (2009). Innovando en educación. Formarse para cambiar: un viaje personal. Barcelona: Erasmus Ediciones.

Kirkpatrick, D.; Kirkpatrick, J. (2006). Evaluación de acciones formativas. Los cuatro niveles. 3a edició. Barcelona: Epise i Ediciones Gestión 2000. 